\section{A NOTE ON THE TREATMENT IN A CASE OF ARTHRITIS DEFORMANS.}

\section{BY FREDERICK BOOTH, M.D. ABERI)}

THE treatment of arthritis deformans is at the present time so unsatisfactory that I have no doubt anything new which has proved successful even in one case will be of interest to the readers of THE LANCET. As there are several recognised varieties of the disease which are probably produced by different causes it will be necessary before describing the treatment to give a brief outline of the case to which I refer.

The patient, a female, aged 29 years, had previously to the attack always enjoyed good health and was strong, robust, and of a cheerful temperament, and there was no history of gout or rheumatism in the family. In January, 1907, she had a mild attack of influenza followed by slight swelling of both ankle-joints which was accompanied by considerable pain felt especially during the night. In February swelling and pain occurred around the first metacarpophalangeal joint of the right hand, the symptoms coming on suddenly, lasting for a few days, and then as quickly disappearing, these attacks recurring at first at long intervals but as time went on more frequently, lasting longer and leaving considerable thickening of the tissues around the joint. Then the other joints, gradually, one after ancther, became affected in the same way and somewhat in the following order-namely, the shoulder, the knees, the elbows, the hips, the jaws, and the spine, until there was hardly one joint in the body which was not more or less attacked by the disease. At first between the attacks there was very little impairment of movement or sign of the interior of the joint being affected, but in the latter stages effusion, especially in both knee-joints, took place. At an early stage of the disease neuralgia appeared, first in the ulnar and circumflex nerves, and gradually extended over the body, the pain and tenderness, though not as a rule severe, being very persistent. Constipation was marked from the onset and the motions became offensive and slimy, although up to that time the bowels had been quite regular. The temperature, though at first only occasionally raised above normal, became persistently so in October, when it generally ranged between $100^{\circ} \mathrm{F}$. in the morning and $102^{\circ}$ in the evening. Emaciation and anæmia were only slightly marked until the fever became constant, when both increased with moderate rapidity. The urine throughout the attack was normal.

At the commencement of the illness aspirin gave great relief, but this eventually lost to a great extent its good effect, whilst other drugs or external applications, though sometimes relieving the pains, had no effect whatever in stopping its progress. On Jan. 24th I advised the washing out of the colon daily with a four and a half feet csophageal tube, using three quarts of warm water in which two tablespoonfuls of Epsom salts were dissolved, the tube being connected with a Higginson's syringe and the water pumped into the intestines as it was gradually inserted, no difficulty being experienced in thus using it. The lower bowel was by this means thoroughly irrigated and the motion which was for the first fortnight offensive and contained a large quantity of mucus gradually improved and became normal. In order to relieve and to disinfect the small intestine a tablespoonful of castor oil was given every morning by the mouth and two compound beta naphthol tabloids B.W. were given three times a day. Nova aspirin was given in 10-grain doses twice a day as the symptoms improved, and later hæmatogen was found to be very beneficial in relieving the anæmia. From the commencement of the washing out of the colon, as above described, the whole of the symptoms improved rapidly, and in a few days the fever and neuralgia had disappeared, the appetite had improved, and the emaciation was less marked. The joints also gradually became less painful and tender and the swelling and effusion slowly subsided. The intestinal lavage was kept up daily until March 14th, then three times a week until May 17th, when the patient went to Buxton, where she is now under the care of Dr. C.W. Buckley, who informs me that the lavage as above described has been gradually reduced to once a week, and the only joint to any extent now affected is the knee, which is improving under subcutaneous injections of fibrolysin.
The above case clearly proves that the disease in this instance was produced from poison generated in the intestinal canal mainly in the large gut. That the small intestine was also infected by the poison was, I think, shown by the fact that when the beta naphthol was not given the motion became more offensive and the improvement for the time was slower. The almost instantaneous disappearance of the neuralgia and rapid diminution of the emaciation were, I think, to be accounted for by the fact that about one-fourth of the water introduced by the tube was retained and this would no doubt be rapidly absorbed and together with the improved appetite would help to fill up the tissues and the salts contained in it would, as I have often found, relieve the neuralgic pains.

St. Anne's-on-the-Sea.

\section{STREPTOCOCCAL ("SEPTIC") THROATS.}

\section{By J. O. HOLLICK, M.B. DuRH., M.R.C.S. ENG., L.R.C.P. LOND.,}

MEDICAL OFFICFR TO T'HE MIDLAND COUN'TIES IDIOT ASYLUM.

IN April, 1908, an outbreak occurred at the Midland Counties Idiot Asylum of a pharyngitis and tonsillitis of an infectious nature, at first thonght to be due to the KlebsLöffler bacillus. Subsequent examination of swabs from the infected throats showed, however, an absence of diphtheria and diphtheroid bacilli but plentiful growth of both streptococci and staphylococci. The examination of swabs was kindly undertaken by Professor R. F. C. Leith, of the pathological department of the University of Birmingham, to whom my best thanks are due for most careful and repeated examinations. The epidemic at first occurred in the nursing staff, a female nurse showing signs of the trouble. It rapidly spread to other nurses on the female side and then to the male nurses, after which several of the male inmates were affected.

The general symptoms are as follows. There is a feeling of malaise, pains in the back and in the neck up to the occiput, and violent headache in a few cases; no vomiting or other abdominal symptoms. The evening temperature often rose to $104^{\circ} \mathrm{F}$. and the morning temperature to $100^{\circ}$. With regard to the throat symptoms, there were slight soreness on one or both sides and difficulty of swallowing; the submaxillary and glands adjacent to the angle of the jaw and in the triangles of the neck were slightly enlarged and tender. On inspection one or both tonsils showed creamy-white secretion with angry-looking areola of inflammation extending to the anterior pillar of the fauces and the urula was often swollen and intensely cedematous. No points of follicular exudation from the tonsils were noticeable. The urine was febrile and in some cases showed a slight trace of albumin, disappearing, however, in from two to three days; no casts or blood were present. The exudation rarely extended beyond the anterior pillars of the fances to the front nor beyond the posterior pillars behind, but much muco-purulent secretion was observed to exude from the lymphoid follicles over the vault of the pharynx ; and signs of nasal obstruction pointing to a general engorgement of the lymphoid tissue around the posterior nares and extending through the nares anteriorly were often evident. The exudate in no case extended over the soft palate or uvula. In from two to four days, according to the severity of the infection, the symptoms and local signs decreased, the glandular swelling and tenderness in the triangles of the neck and at the angle of the jaw remaining for some days or weeks after the clearing up of the throat symptoms. In connexion with this epidemic two cases of cutaneous erysipelas of the foot and leg occurred: both patients had slight abrasions of the skin previously, one of the skin between the toes and one of the skin over the dorsum of the foot. The temperature of both cases at once rose to $103^{\circ}$ and $104^{\circ}$ respectively. 20 cubic centimetres of antistreptococcic serum (Lister Institute) were administered subcutaneously into the skin over the abdomen. A marked fall of temperature occurred in each case during the next 24 hours, with, however, little abatement of the local signs of cutaneous inflammation; neither case suppurated, but convalescence was tardy owing to extremely slow subsidence of local inflammatory signs. Several of the patients with the throat symptoms and glandular enlargements showed a tendency to relapse if allowed to get up within too short a period of subsidence of 
temperature; the relapses in these cases, however, were never so severe as the primary manifestations, 48 hours in jed again bringing the temperature to normal.

With regard to treatment, all these cases were isolated at once on rise of temperature, however slight, or on complaint of soreness of throat, and owing to this precaution in a colony of 160 people only 15 were affected with the malady. Formalin tablets were vapourised daily and freely in all dormitories and day rooms while the inmates were out of doors. Formamint lozenges were sucked (three a day) by all not affected, and by those affected a lozenge every three hours, while frequent swabbing of the tonsils and pharynx with "izal" solution (suitably diluted) was resorted to. All cups, spoons, \&c., used by the affected inmates were sterilised in formalin solution after use. In addition to the swabbing, spraying of the pharynx and nares with the formalin spray was also carried out. I might mention that the place where this outbreak occurred is situated in a healthy part of the country 800 feet above sea level, where drainage and other sanitary arrangements are carried out on the most approved and modern lines. There are no poultry or cattle, \&c., kept near the premises.

No sooner had this epidemic abated than one of a similar but more severe nature occurred in my practice here at a private preparatory school, consisting of 40 pupils with staff of masters, head master's family, servants, \&c., numbering upwards of 60 people in all. The building is healthily situated, 400 feet above sea level, in the country, and remote from anv other dwelling. The sanitation of the whole building had just been completed at a cost of $£ 200$, with drainage into a "septic tank" some distance from the building. A few fowls, horses, pigs, cows, \&c., are kept near the premises, but there is allowed no offensive accumulation of excreta from these sources. The analysis of drinking-water was satisfactory. The pupils live an out-of-door life as much as possible and practically at this time of the year (May and June) are only indoors at lessons, meals, and to sleep. The building is constructed with the view to the admittance of as much light and fresh air as possible; all windows open widely and are kept open as much as existing conditions of weather permit. There was a history, before the commencement of the epidemic, of one boy returning to school who had had sore throat which had imperfectly cleared up. In from two to three weeks later a boy was seized with convulsions. I saw him soon after the abatement of the seizure. His temperature was $103^{\circ} \mathrm{F}$; he complained of no sore throat, but his cervical glands were enlarged and tenuer. He was isolated at once. On seeing him next day he had a creamy secretion over both tonsils but not extending on to the palate, uvula, or faucial pillars. There was much angry congestion over the latter, and he now complained of much difficulty and pain on swallowing.

Four other boys on this day were put to bed with rise of temperature, tenderness over the cervical glands, headache, malaise, and some pain on swallowing on one or both sides. One of these showed much more cervical glandular enlargement and had a more suspicious look about his fauces and tonsils than the rest. Moreover, he had signs of much nasal obstruction and he was isolated. A swab from his throat showed Klebs-Löffler bacilli. He was treated with 4000 units of antitoxin, swabbed with izal, sucked formamint lozenges, and the usual treatment was carried out by both night and day nurses. He proved to be a severe case of diphtheria of the fauces and nares, with marked heart and kidney trouble, and succumbed 14 days after onset of symptoms to cardiac failure.

Swabs from other throats showed Hofmann's diplococci and streptococci but no diphtheria bacilli. Boys fell down like ninepins, whole classes going sick one by one, all with similar symptoms and local signs. One boy, and only one, had middle-ear trouble ending in suppuration, with no mastoid complication. Repeated swabs were taken for examination. The specific bacillus was only found in one other case of the 30 affected, and in this boy local throat signs were slight, but he was isolated and had no ill after-effects; in fact, his malady was of so slight an importance to him that he never really complained of feeling ill. He had no abnormal gland swelling and no nose trouble. A feature of this epidemic and one that was so very striking that the veriest tyro on throat affections could not have failed to notice it, was the comparative slightness of the internal (tonsillar and pharyngeal) signs in the older boys of from 12 to 14 years of age, with in some cases no secretion or exudation, and the mildness of their constitutional symptoms; while the younger boys of from 10 to 12 years of age had sharp febrile disturbance, with much pain in the throat and glands and took much longer time to convalesce, whilst the subsequent anæmia was often very marked. Some showed signs of heart dilatation, some had none. Most had tenderness with swelling of the glands at the angle of the jaw and around the sterno-mastoid. In some cases slight, in others very marked, glandular enlargement was noticeable, taking many weeks to subside to the normal. Some, again, had albuminuria, mostly of a very transient nature, only lasting from three to four days. Some had none, and in no nondiphtheritic case was there a true nephritis or endocarditis. One boy in whom a tonsillotomy had been done a year or so previously acquired the disease and had a very sharp attack. Several of the cases developed dilated hearts with apex beat well out in the mid-axillary line. This complication, however, cleared up with prolonged rest. Appetite was good, almost ravenous, even though much secretion and faucial swelling were present; headache was persistent in a few cases, little or absent in most. There was no doubt about the izal swabbings and sucking of formamint doing good in checking the amount of secretion and local pain on swallowing. Several cases had to return to bed after getting up in the dormitory for a short time after the temperature had been normal for several days and secretion had disappeared. This was in most cases due to a secondary adenitis in the cervical glands, even in those who had had previously but slight. gland trouble, yet the relapse was often more severe than the primary adenitis and much more obstinate in clearing up. No case went on to suppuration. In several the pharyngeal tonsil and adjacent lymphoid tissue showed signs of congestion for from two to three weeks after disappearance of throat discomfort and the nares were in a few cases slow to resume their normal appearances. Some made rapid strides in convalescence, others remained anæmic for from three to. four weeks, and in one case, after the boy had been sent home and had been resting in open air for three weeks after the attack, news was received of his having to take to bed again with rise of temperature and return of his former gland symptoms.

This all points to the persistence of the infection even after a period of apparent normal health; the streptococcus, no doubt, can linger on in the remote parts of the fauces, nares, Eustachian tubes, and query in the cervical glands even after all symptoms of the affection are past and done with. Hæmatogen and maltine with iron ("bynophosphates") seemed to do most good as an after tonic, and the incidence of warm sunshine in the latter part of June seemed to put a check to the spread of the infection. A notable feature of the epidemic was a slight pharyngitis experienced by the adult people (masters and servants) of the school with no serious constitutional disturbance; this was not fanciful but real, as I had an opportunity of examining the fauces of those affected.

My reasons for reporting these two epidemics are, filstly, the now well-understood possibility of a "diphtheritic" supervening on or accompanying a "diphtheroid" infection ; and, secondly, of a streptococcal infection (with staphylococcal) going hand-in-hand with both and gaining sometimes the upper hand, and so minimising the risks run had the former reigned alone supreme, and that none the less is a streptococcal throat infection to be treated lightly, owing to the persistent and clinging properties of the micro-organism resulting in much adenitis and subsequent constitutional disturbance and anæmia.

I had almost hoped for a case of scarlet fever to crop up during the course of this epidemic to add further evidence to the well-known "possibilities" of micro-organisms of the streptococcal group. My expectations were ultimately realised, for in a family of six children residing in an isolated country cottage five developed streptococcal throats, all females, while the sixth child, a boy, aged six years, developed true scarlet fever in a very typical form : he desquamated freely and in eight weeks had finished peeling and was in good health. From the three epidemics, then, described above, in three separate households, streptococci were found to be present in the throat swabs in all three instances, and the possible and various results of streptococcal infection were well illustrated in the production of a tonsillitis, an erysipelas, and scarlet fever.

Knowle, Warwickshire. 